\title{
Survey timing vs. ecosystem scheduling: Degree-days to underpin observed interannual variability in marine ecosystems
}

\author{
Huret Martin ${ }^{1,{ }^{*}}$, Bourriau Paul ${ }^{2}$, Doray Mathieu ${ }^{2}$, Gohin Francis ${ }^{3}$, Petitgas Pierre ${ }^{2}$ \\ ${ }^{1}$ Ifremer, STH/LBH, B.P. 70 29280, Plouzané, France \\ 2 Ifremer, EMH, rue de l'île dYeu, BP 21105, 44311 Nantes Cedex 03, France \\ ${ }^{3}$ Ifremer, DYNECO-PELAGOS, B.P. 70 29280, Plouzané, France \\ *Corresponding author : Martin Huret, email address : martin.huret@ifremer.fr
}

\begin{abstract}
:
Fishery annual surveys are shifting towards integrated ecosystem surveys. However, monitoring the whole ecosystem once a year entails special attention to the interpretation of observations, because they only represent a snapshot in the seasonal dynamics of the environment, of a species, or any dynamic process of interest. The dependency of this snapshot to the timing, but also to the duration, of the survey with respect to this seasonal dynamics needs to be considered. Fish stock assessment is only little impacted by the observed timing within a given season, whereas warming, stratification, plankton bloom occurrence, or fish fecundity, are processes rapidly changing especially in spring. Firstly, from independent satellite data, we described the seasonal and interannual Sea Surface Temperature (SST) variability in the Bay of Biscay in spring around the annual PELGAS surveys. Our results revealed that the in-situ surface temperature snapshot from a given survey may be strongly misleading on the existing spatial pattern, blurring the latitudinal temperature gradient, with potential impact in e.g. species habitat modelling. Secondly, based on these survey-independent SST data, we proposed a methodology to position annual surveys in the environment spring schedule. Our temporal indicator is based on a degree-day metric, computed as the cumulated temperature from the previous winter date with minimum annual temperature. The annual degree-day is then compared to the climatology of the degree-day metric to correct the actual date of survey to an environment date. The methodology was spatialised to take into account both latitudinal shift in phasing of seasonality, and rapidly changing conditions in the environment during the survey itself. Finally, we tested the methodology to refine the description of anchovy and sardine spawning phenology, as well as spawning spatial distribution for particular years such as hot year 2003. More generally, this is an example of how synoptic, independent data from operational oceanography, as a background history of the environment dynamics, can be used to improve the interpretation of biological observations in marine ecosystems
\end{abstract}




\section{Highlights}

- A degree-day metric from satellite Sea Surface Temperature data in the Bay of Biscay. It is used to position annual surveys within the environment seasonal scheduling. Anchovy and sardine spawning observations are interpreted based on this schedule. Survey-independent data are really valuable in interpreting survey observations.

Keywords : Ecosystem survey, Anchovy, Sardine, Spawning, Sea surface temperature, Degree day, Bay of Biscay 
Routine annual surveys are performed in many marine regions to provide fishery independent estimates of fish biomass for stock assessment groups delivering management advices. These surveys are evolving to become ecosystem monitoring surveys, when the vessel platform

50 allows for the additional sampling effort required. This is the case with the PELGAS (PELagiques GAScogne) survey in spring in the Bay of Biscay (Doray et al., this issue). The Marine Strategy Framework Directive (MSFD, 2008/56/EC) has rationally built a large part of its monitoring strategy on these existing ecosystem surveys and associated research vessel platforms (Shephard et al., 2015), at least over its offshore domain, in a context of optimisation of the data collection effort

55 (Borja and Elliott, 2013).

If monitoring is to rely, even partially, on surveys performed on an annual basis, then it is logical to question the meaning of observed variability between surveys, which provide only a snapshot of any variables of interest and on the state of the ecosystem. In other words, are interannual variations in survey parameters, or indicators, caused by an effective change in the

60 ecosystem state ? Or is it just that the ecological timing between annual surveys is lagged by a few weeks without real significance on the ecosystem on the annual scale ? In the former case, timeseries of indicators can be analysed to characterise trends or singular years. In the later case, interpretation require more precautions, and needs to consider the short-time scale variability that may strongly influence the snapshot picture that is derived from each annual survey. In the same

65 manner that setting a Good Environmental Status for an ecosystem requires defining a reference state (Borja et al., 2012), the usefulness and robustness of an indicator that is seasonally variable but yearly monitored may only hold if its seasonality is assessed and understood.

Another related question arises from the duration of the surveys, generally lasting over several weeks. The PELGAS survey lasts over a month in the Bay of Biscay, a system known to 70 change rapidly in spring (Koutsikopoulos and Le Cann, 1996) as in other temperate regions. The 
survey then integrates part of this evolution, and the state of the ecosystem may well be strongly different between the beginning and the end of the survey when referring to a seasonal ecosystem scheduling.

When sampling fish populations that are rather stationary in space during their spawning 75 season, ensuring whole population coverage takes priority over considerations on the survey duration. In contrast, survey duration becomes a strong source of variability for parameters affected by rapid seasonal change. This is the case for the physical environment, especially in spring when warming and stratification occur rapidly, as well as for most lower trophic levels (i.e. phyto- and zooplankton) that respond to the physical environment and have their own, and often fast,

80 population dynamics. This is also the case for fish spawning activity, which may be quite variable around the timing of peak spawning, in part because of its high dependency on the physical and biotic environment. Annual fish assessment surveys are scheduled every year at the same period, but even in that case strong interannual variability may be observed (e.g. Doray et al., this issue) and it is not an easy task to disentangle the effects of factors intrinsic to the variable under study

85 from that of the external factors, i.e. the interannual variability in its abiotic or biotic environment.

PELGAS was initially scheduled in spring and centered in mid-May to target anchovy aggregation during its peak spawning (Motos et al., 1996). In parallel to the acoustics, egg sampling is performed continuously with the Continuous Underway Fish Egg Sampler (CUFES, Checkley Jr et al., 1997). CUFES data were used with two objectives. The first one being the provision of an

90 egg abundance index as an additional proxy to the stock biomass index derived from acoustics (Petitgas et al., 2009). The second aims at understanding spawning activity and habitat (Bellier et al., 2007; Planque et al., 2007). For both objectives, it is important to understand what controls the observed interannual variability in spawning intensity as estimated by the egg abundance index. This means trying to disentangle the effects of intrinsic population factors, i.e. the spawning stock

95 biomass (SSB) or age and/or size structure, from that of the extrinsic factors, i.e. past seasonal history of temperature and food abundance impacting reproductive potential. 
The ecosystem snapshot captured during the survey may be set in a broader seasonal context with the help of Earth Observation (EO) systems (Donlon et al., 2012) or modelling systems (Sotillo et al., 2015), and more generally of the Operational Oceanography (OO). The main 100 objective of this paper is to propose a methodology for positioning the annual surveys in a climatological environment schedule, used as a reference, with the help of external information from satellite data. The Sea Surface Temperature (SST) is chosen here for the essential role of temperature in physiological and ecological processes and for its availability as homogeneous and synoptic data over the whole PELGAS time-series. The temperature itself, taken instantaneously, can only be a poor predictor of what is measured during a survey, for example fish parameters such as size of fecundity resulting from development. Life history traits such as growth or reproduction phenology, like for many ectotherms, are instead the result of the temperature integral (Neuheimer and MacKenzie, 2014; Neuheimer and Taggart, 2007). This was the fundamental basis for the development of the degree-day approach by agroculturalists almost three centuries ago (see review

110 by Bonhomme, 2000). The growing degree-day metric, the time integral of the daily temperature measured above a temperature threshold, has been widespread since, to predict crop growth and phenology. In comparison, the approach has been overlooked in fish science (Neuheimer and Taggart, 2007). In this paper a degree-day approach is used, with the cumulated daily SST from end of winter, as a starting point of seasonal warming. The degree-day metric is used to position each

115 annual survey in the environment seasonal schedule in order to help interpreting the variability between years on some of the measured variables during the surveys. The methodology is then applied to characterise the variability in anchovy and sardine egg abundances, and to refine the description of the springtime spawning curves of these two important commercial species in the Bay of Biscay. 


\section{Material and methods}

PELGAS annual surveys

The ecosystem PELGAS surveys (Doray et al., this issue), 2000-2016, were undertaken by IFREMER on board RV "Thalassa" over the French shelf of the Bay of Biscay in spring. The survey design was made of parallel line transects, perpendicular to the isobaths and regularly spaced 12

125 nautical miles (n.m.) apart, from $43^{\circ} \mathrm{N}$ to $49^{\circ} \mathrm{N}$ and from coast (20 $\mathrm{m}$ depth) to the shelf break (Fig. 1). See Doray et al. (2014) for details on PELGAS survey protocols. All surveys were conducted from south to north except in 2001 when it was performed the other way round.

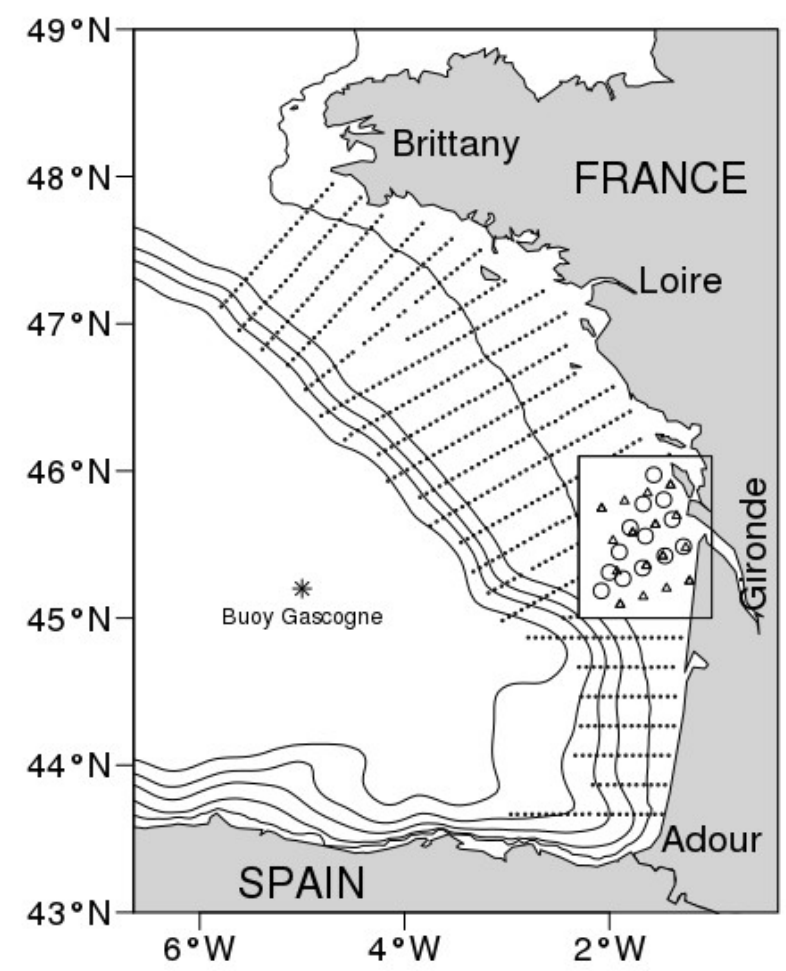

Fig.1. Map of the study area with CUFES sampling (dots) along transects during PELGAS surveys, and in

130 the Gironde plume during PLAGIA (1999, triangle) and ECLAIR (2008, circle). PELGAS sampling locations were removed from the Gironde plume area in the figure for more clarity of sampling stations during PLAGIA and ECLAIR. The isobaths 100, 200, 500, 1000 and 2000 are drawn, as well as main rivers (Loire, Gironde and Adour) used in the text. 
SST is obtained from the Ifremer SST data derived from AVHRR/Pathfinder daily products interpolated by kriging (Saulquin and Gohin, 2010) for the period 1986-2009; the OSTIA data provided by the Met Office using the Operational SST and Sea Ice Analysis (OSTIA) system described in (Donlon et al., 2012) for 2010; and the ODYSSEA data, also derived from multi-sensor

140 data set incorporating microwave instruments, provided by MyOcean (Autret and Piollé, 2011) for the period 2011-2016. A comparison with an homogeneous time series covering the entire period, stemming from global low-resolution GHRSST, showed that the inhomogeneity of the highresolution time series used here did not generate bias (L'hévéder et al., 2017). The three sets of SST data were projected onto the same grid with a mesh size of $1.2 \mathrm{~km}$ but, due to the input data, the

145 effective resolution of the SST products is in reality approximately $4 \mathrm{~km}$. In addition to satellite information, CTD casts (Seabird SBE19+V2) are performed at night during PELGAS. 4 to 7 stations are performed every other transects of Fig.1, for a total of almost a hundred per year. In-situ SST at each station is computed by averaging temperature from surface to $5 \mathrm{~m}$.

\section{Egg sampling during PELGAS}

During daytime, the Continuous Underway Fish Egg Sampler (CUFES, Checkley Jr et al., 1997) is used for sampling every $3 \mathrm{~nm}$ (approximately $18 \mathrm{~min}$.) along the transects (Fig.1) with the vessel operating at a speed of 10 knots. The CUFES samples a depth layer comprised between 3 and $5 \mathrm{~m}$. Anchovy and sardine eggs are sorted and counted, and surface concentrations are derived based

155 on the CUFES flow. To take into account the spatial and interannual variability in the vertical distribution of the eggs, an egg vertical distribution model was used to estimate the vertically integrated total egg abundance based on the surface concentration sampled by the CUFES. For that an update of the vertical distribution model of Petitgas et al. (2006) was used with the egg specific 
gravity models for both species detailed in Huret et al. (2016).

160

Monthly egg sampling in the Gironde plume

Monthly repeated surveys were performed in the Gironde plume (Fig.1) in 1999 (PLAGIA surveys, February to July) and 2008 (ECLAIR surveys, March to August, Huret et al., 2016). During PLAGIA, fish eggs were sampled with the 'Filet Carré' net (Bourriau, 1991) hauled at 2

165 knots for 5 to $10 \mathrm{~min}$. in the surface mixed layer (from surface to bottom of the thermocline and back to surface). During ECLAIR, they were sampled vertically at station with the WP2 net from bottom to surface. Only anchovy eggs were identified and available from PLAGIA surveys while both anchovy and sardine eggs are available in the ECLAIR dataset. Egg concentrations were derived from the use of a flowmeter.

170

Spatialising the analysis

CUFES samples were collected at high temporal and spatial resolution, as compared to the satellite images. In order to standardise the analysis and work with the same resolution, both egg and SST data were spatially smoothed over the same grid, to produce standard gridded maps (cf.

175 Petitgas et al., 2009). The grid mesh size selected was $0.25^{\circ}$ in both directions, with origin $\mathrm{x} 0$ at $43^{\circ} \mathrm{N}$ and $6^{\circ} \mathrm{W}$. This grid was chosen as a compromise between the number of CUFES samples averaged in each block (or cell), and the grid spatial resolution. For each variable, the mean in block (i, $\mathrm{j}, \mathrm{x} 0$ ) was the simple average of the data inside the block, positioned at the block centre. To decondition the block means from the grid origin, the point origin $\mathrm{x} 0$ was randomised in the lowest

180 left corner block 100 times. The 100 values computed within each block were eventually averaged to provide the final parameter estimate in the block. Finally, estimation of egg concentration and SST were available at the scale of the blocks. They were also estimated for the whole survey area by computing the average (SST) or sum (egg abundance) over all map block values weighted by the 
surface of each block.

Degree Days

Our aim was to find an objective way of interpreting some biological observations from the PELGAS surveys, with a specific focus on anchovy and sardine egg abundances. The degree-day is now recognised as having a strong explanatory power in fish growth and maturity (Venturelli et al.,

190 2010) as well as in spawning phenology (Neuheimer and MacKenzie, 2014). The degree-day, as the time integral of daily temperature above a temperature threshold, reflects the cumulative effect of metabolism over a development period, within the normal temperature range for a given species. Here, the degree-day approach is computed and used as an indicator of the timing of each annual survey, with respect to an environment seasonality as provided by the SST daily climatology. As

195 such, the degree-day metric is not of interest by itself, but it is used to correct the actual date of the survey to an environment meaningful date.

A first difficulty in the computation of the degree-day metric lies in the assessment of temperature experienced by the organism in the field. Small pelagic fish move during the day-night cycle throughout the water column, which can display strong vertical temperature gradient as

200 stratification strengthens in spring. It is then impossible to get an accurate temporal estimation of experienced temperature. The SST variable we used then only represents a proxy, as fishes only spend part of the day in surface layers, but it has the advantage of integrating the seasonal warming, contrary to bottom temperature. A second difficulty lies in the selection of the starting date to compute the time integral of temperature, which will be process and species dependent. Our

205 objective being to remain as generic as possible for the interpretation of diverse parameters observed during the survey, we have sought a generic and ecologically meaningful date. The end of the winter period displays the minimum annual SST in the Bay of Biscay, as well as the minimum interannual variability in SST (lowest coefficient of variation (CV) in March, see Fig.2). As such, 
the end of winter could be considered as the annual reset in terms of warming and biological 210 activity of most ecological processes following the seasonal cycle in the pelagic realm. For our study, the end of winter hence represents a good starting point for the annual integration of the degree-day function from the beginning of the year to the survey time period. This starting point is taken more precisely as the day of the annual minimum of the SST daily climatology, occurring in early March in our area (Fig.2).

The degree-day is computed locally for each block, considering local SST climatology and its own corresponding date with annual minimum. Our Degree-Day (DD) variable at average date $\mathrm{d}_{\mathrm{s}}$ (in day) of sampling in block b of year y is calculated with the following equation :

$$
D D\left(y, b, d=d_{s}\right)=D D(y, b)=\sum_{t=d_{\operatorname{Tnn}}(b)}^{t=d_{s}(y, b)} \operatorname{SST}(y, b, t)
$$

with $\mathrm{d}_{\text {Tmin }}$ (b) the day of the year at which SST climatology value for block b is minimum, and $220 d_{s}(y, b)$ the average date (in day) of sampling in block b of year y. Let $D_{\text {clim }}(b, d)$ be the DD calculated on the SST climatology $\left(\operatorname{SST}_{\text {clim }}(b, d)\right)$ for every date $d$ starting from $\mathrm{d}_{\text {Tmin }}(\mathrm{b})$. The function $\mathrm{DD}_{\text {clim }}(\mathrm{b}, \mathrm{d})$ monotonically increases with d over the period of interest from March to the beginning of summer, providing a unique date $\mathrm{d}=\mathrm{d}_{\text {cor }}(\mathrm{y}, \mathrm{b})$ for which $\mathrm{DD}_{\text {clim }}(\mathrm{b}, \mathrm{d})=\mathrm{DD}(\mathrm{y}, \mathrm{b})$. This date $\mathrm{d}_{\text {cor }}(\mathrm{y}, \mathrm{b})$ is the local, corrected, ecologically meaningful date for any location and annual PELGAS survey. As 225 for SST or egg abundance, a corrected date of survey $\mathrm{d}_{\text {cor }}(\mathrm{y})$ can be computed per year by averaging the block values. 


\section{Results}

\section{Seasonal warming}

The rate of surface warming in the Bay of Biscay is strongest in spring and more precisely in May-June, according to the daily SST climatology averaged over the whole bay (Fig.2). Warming starts in March, intensifies in April, and slows down in July. The interannual variability characterised with the coefficient of variation (CV) calculated on both satellite and in-situ data (Fig.2) is also highest from late April to the summer. The CV calculated on in-situ data at off-shelf

235 buoy 'Gascogne' is lower than satellite-derived CV in winter, likely due to a lower influence of coastal processes such as tide and plumes that may generate their own variability. Unfortunately no coastal station provide long enough SST time-series in the area so far, though analysis over few years reveal more homogeneous variability along the season (not shown). The important point here is the fact that the interannual variability strongly increases in early spring, consistently from both

240 sources of data. The CV varies quite a lot at high frequency, likely due to the relatively low number of years available to compute it. In particular a minimum CV value appears in mid-May, suggesting less interannual SST variations during this period, following high interannual variability in lateApril to mid-May and before June (day of year 150). This is not clear whether a larger number of years would homogenise the CV over the spring period. But in any case, the timing of the PELGAS

245 surveys, centered in May, places it in a rapidly changing environment, with strong interannual variability, at least in terms of temperature. 


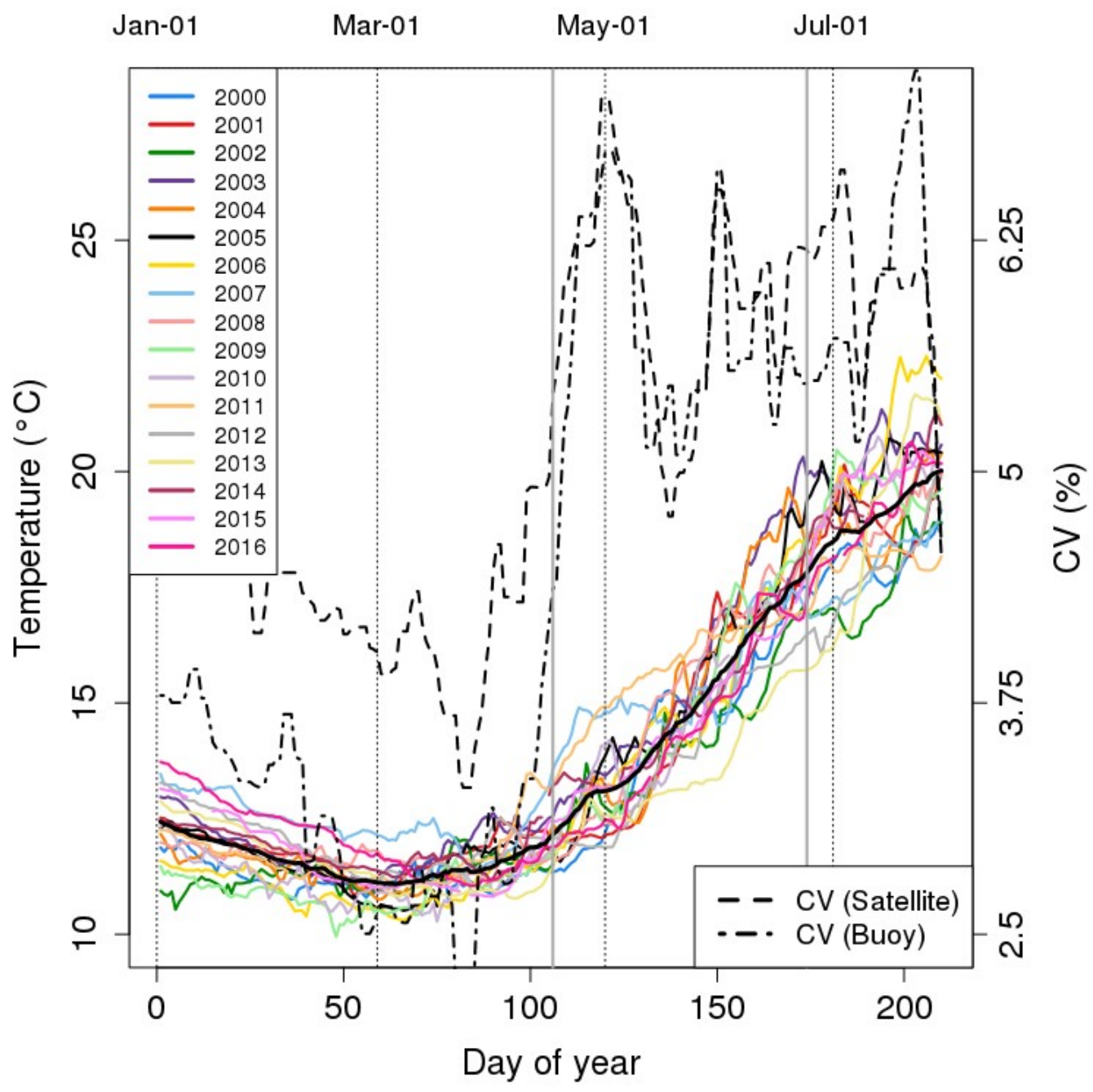

Fig.2. Times series of satellite-derived daily SST averaged over the PELGAS survey area in the Bay of Biscay for the first part of each year between 2000-2016. Continuous black line is the associated daily climatology. Dashed line is the associated CV (Coefficient of Variation of the interannual variability, \%). Dashed-dotted line is the CV calculated from in-situ data (1999-2016) at Buoy 'Gascogne' (62001; 5 W;451' $N$, see Fig.1). Vertical grey lines encompass the survey dates over all years.

255 Spatio-temporal variability of temperature during PELGAS surveys

Surface temperature in spring shows a latitudinal gradient in the Bay of Biscay with generally 2 to 3 degrees more in the south-east than in northern Biscay, as exemplified with year 2016 in Fig.3 (b,c,d). The duration of the survey of about a month has the general effect of blurring this instantaneous latitudinal gradient, even reversing it at some locations (Fig.3a) and years. Indeed, the surface warming of 2 to 3 degrees per month (in each block) in spring (Fig.2) equals the spatial 
instantaneous gradient.
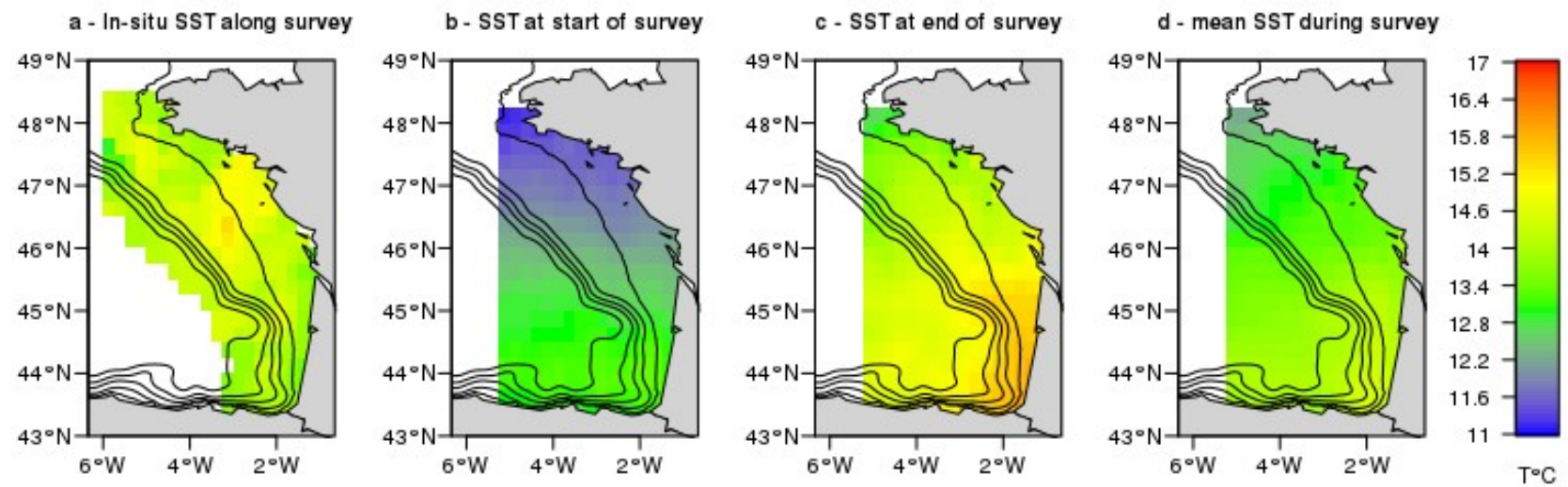

Fig.3. Sea Surface Temperature in 2016 from (a) survey CTDs, satellite at (b) start and (c) end of survey, and (d) average satellite SST over the duration of the survey.

Correcting the survey dates with the seasonal degree-day schedule

Correcting the survey dates using the degree-day approach by block generates some variability in the timing of the survey, with respect to the SST seasonality (Fig.4). Generally when a survey starts at a temperature higher than the climatology (i.e. the corrected date is translated after the actual one), then the temperature remains higher than the climatology over the duration of the survey (e.g. 2003, 2007, 2011, 2014, see Fig.4a). The opposite is also true (e.g. 2013). However for some years, especially 2000 during which the temperature rapidly increased during the survey, corrected dates are largely translated before the actual dates at some locations (south and midlatitude offshore, Fig.4a and Fig.5), while survey dates are only slightly shifted in the north-east.

The survey date correction leads to several other consequences that are worth noting. In the case of 2000, which was the earliest survey of the series (centered on May ${ }^{\text {st }}$ ), corrected dates are translated even earlier with an average corrected date shifted to early April. In the same way, 2003, the survey that took place the latest in the series, is shifted 10 days later, to the second part of June 
corrected dates, with much more variability in the sampling dates (Fig.5). As the survey has taken place more or less at the same time since 2004, some years are shifted earlier (2006, 2009-2010, 2013) and others later (2007, 2011, 2014), generating some variability in the measured temperature, but also likely in other environment parameters. Finally, considering the duration of the survey of 285 about one month, together with the evolution of temperature during the survey, the survey date correction involves either an extension (e.g. 2000, 2005, 2009, 2012 and 2015, Fig.4b) or less often a reduction, not really significant though, of the corrected survey duration (2002). In the former case a larger range of temperature is observed, and a smaller range in the later case.
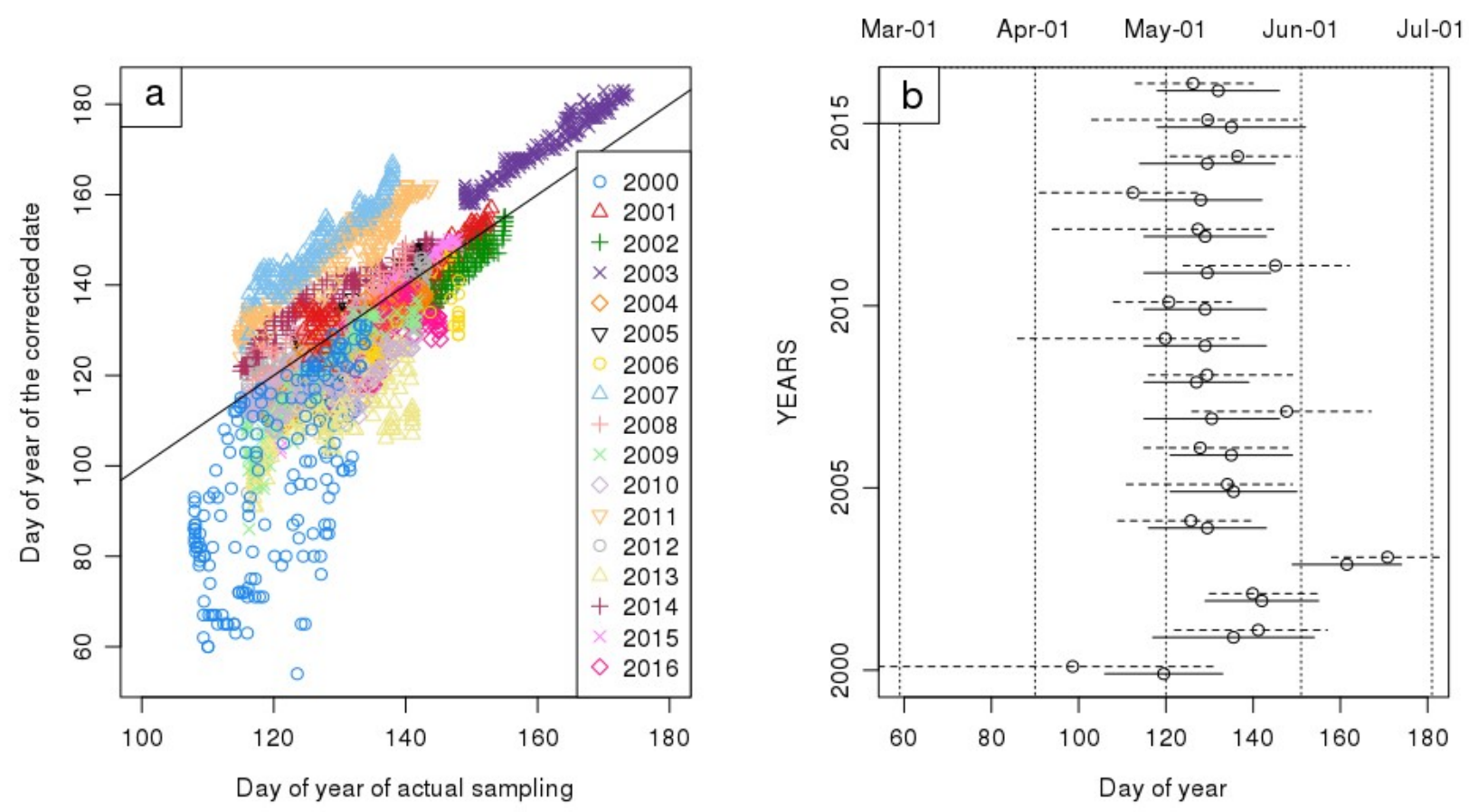

290 Fig.4. Comparison between actual sampling date and corrected date for the PELGAS annual surveys. (a) Comparison at the scale of the blocks. Black line is the first bisector. (b) Duration of annual Pelgas surveys with actual dates (continuous segment) and corrected dates (dashed segments). Dots are for average date from block dates. 

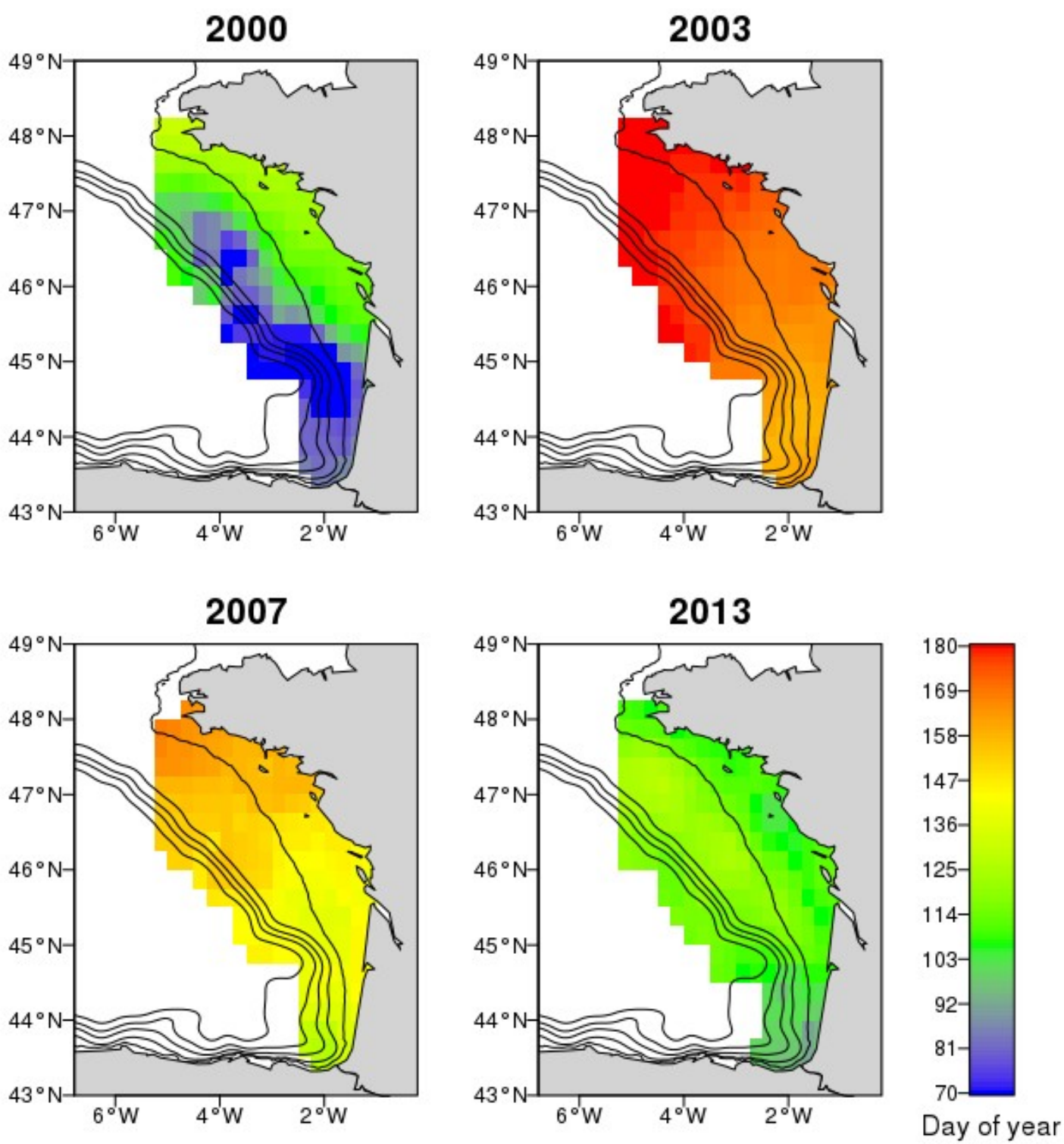

295

Fig.5. Maps of locally corrected dates of sampling for contrasted years.

Spawning patterns

The average spatial patterns of spring spawning fish observed during PELGAS (17 years) are summarised in Fig.6. Anchovy spawning is mostly located in the southern part of the bay with a maximum on the inner shelf in front of the Gironde estuary. Anchovy egg production is high all over the shelf and shelf break in the south, with another maximum at the extreme south which corresponds to the Adour river plume (see location on Fig.2). Sardine spawning generally overlaps 
with anchovy in the south, but peak abundances are lower, and maxima appear closer to the coast in southern Biscay and more off-shore at the latitude of the Gironde. Sardine spawning also extends further north, both along the coast, with a maximum in the vicinity of the Loire plume, and over the shelf break, but is absent over the mid-shelf. The interannual spatial variability (CV map, Fig.6) is generally inversely correlated with the egg abundances, except in the north for sardine where it can be high in the vicinity of the shelf break. CVs are generally higher at the edges of the spawning distribution. Fig.7 shows the fish egg distributions for singular years, selected based on the corrected dates presented in Fig.4. 2000 and 2003 are the most extreme years based on the date correction procedure, 2011 has one of the latest corrected date together with the highest egg

315 abundance observed over the time-series. Anchovy spawning in years 2003 and 2011 shows a more northward extension along the coast, especially along the shelf break, as compared to year 2000. The most striking difference in sardine spawning lies in the difference of abundance between 2000 and 2003. Between 2000 and 2011, the shift in the north between offshore and coastal dominance is also remarkable. 

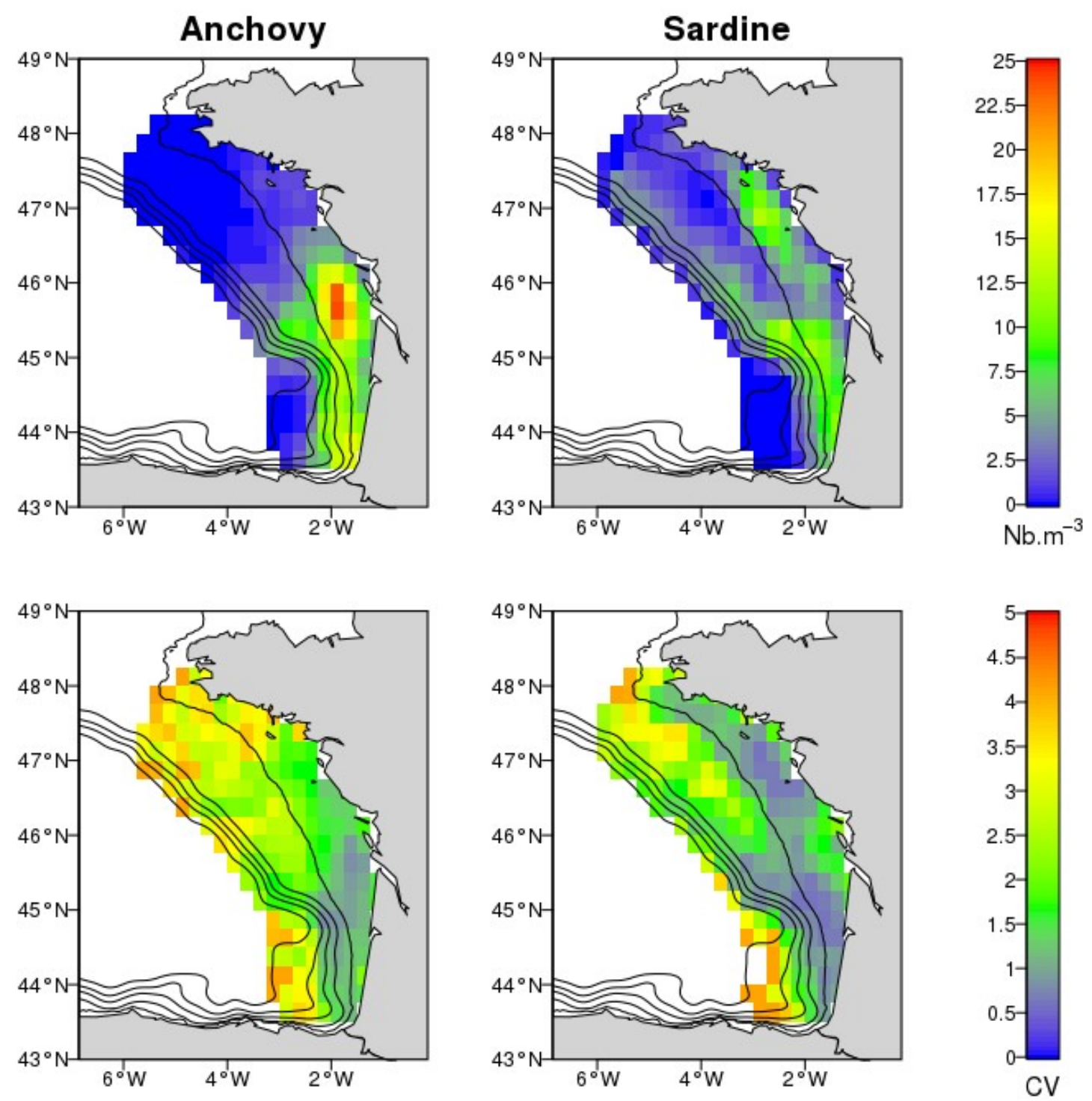

Fig.6. Average (top) and CV (bottom) maps of egg abundance for anchovy (left) and sardine (right) during Pelgas spring surveys (2000-2016) from CUFES surface sampling. 

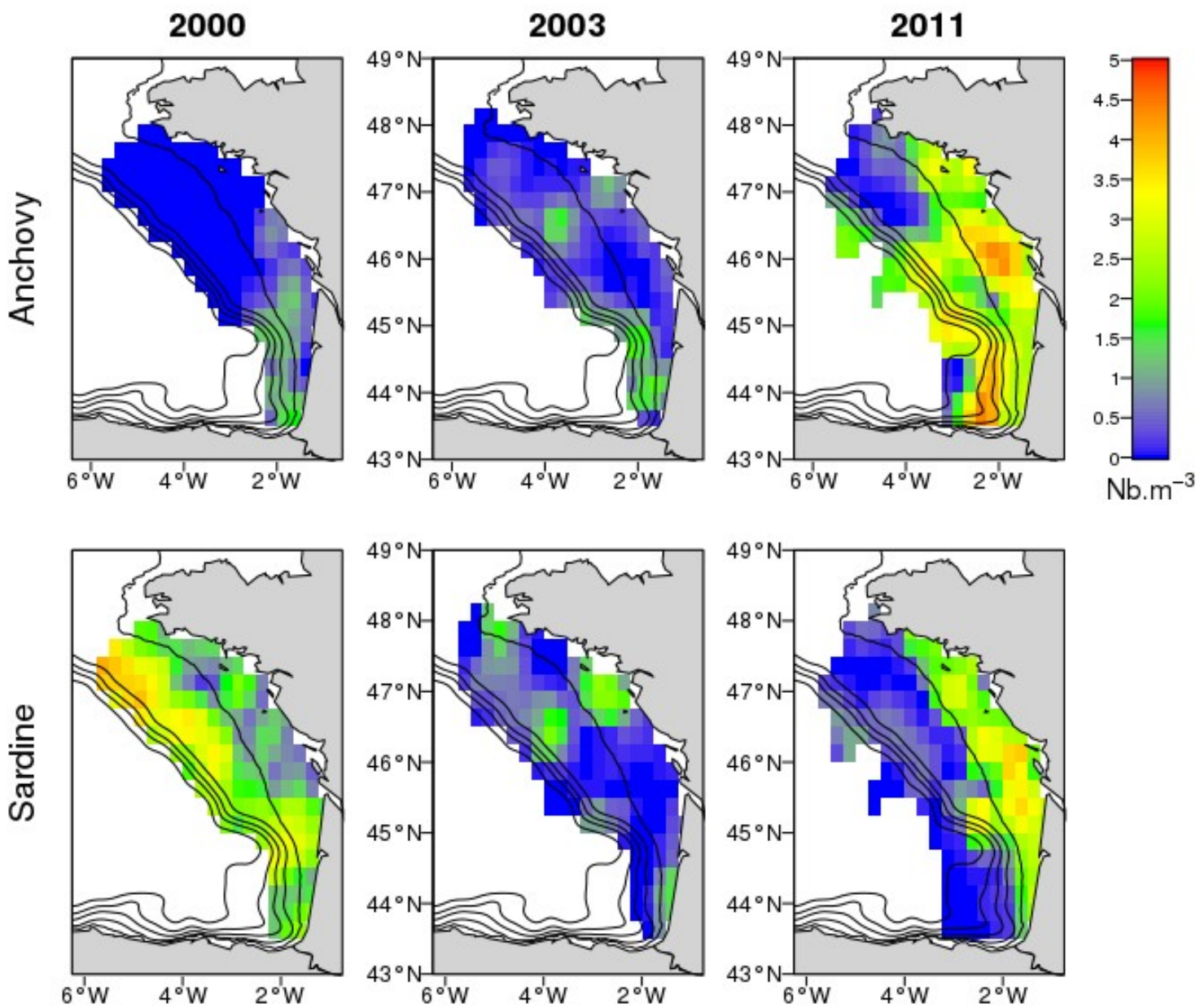

Fig.7. Egg distribution for most singular years according to the corrected dates of survey (2000 and 2003, see Fig. 4) for anchovy (top) and sardine (bottom). 2011 is also singular in terms of anchovy egg abundance. Abundances $(x)$ have been $\log (x+1)$ transformed before mapping.

Anchovy spawning in the Gironde plume starts in April and sharply increases in late April, according to data collected in 1999 and 2008 during the PLAGIA and ECLAIR surveys, respectively (Fig.8). The peak spawning extends from early May to late June, and spawning seems to occur until August with a slow decrease throughout summer. Sardine spawning starts earlier than anchovy, with a real starting date that was not captured in 2008. Some sardine spawning was detected in March, the peak seems to cover the period of April - early May, whereas spawning activity decreases rapidly in June to become negligible in summer. 


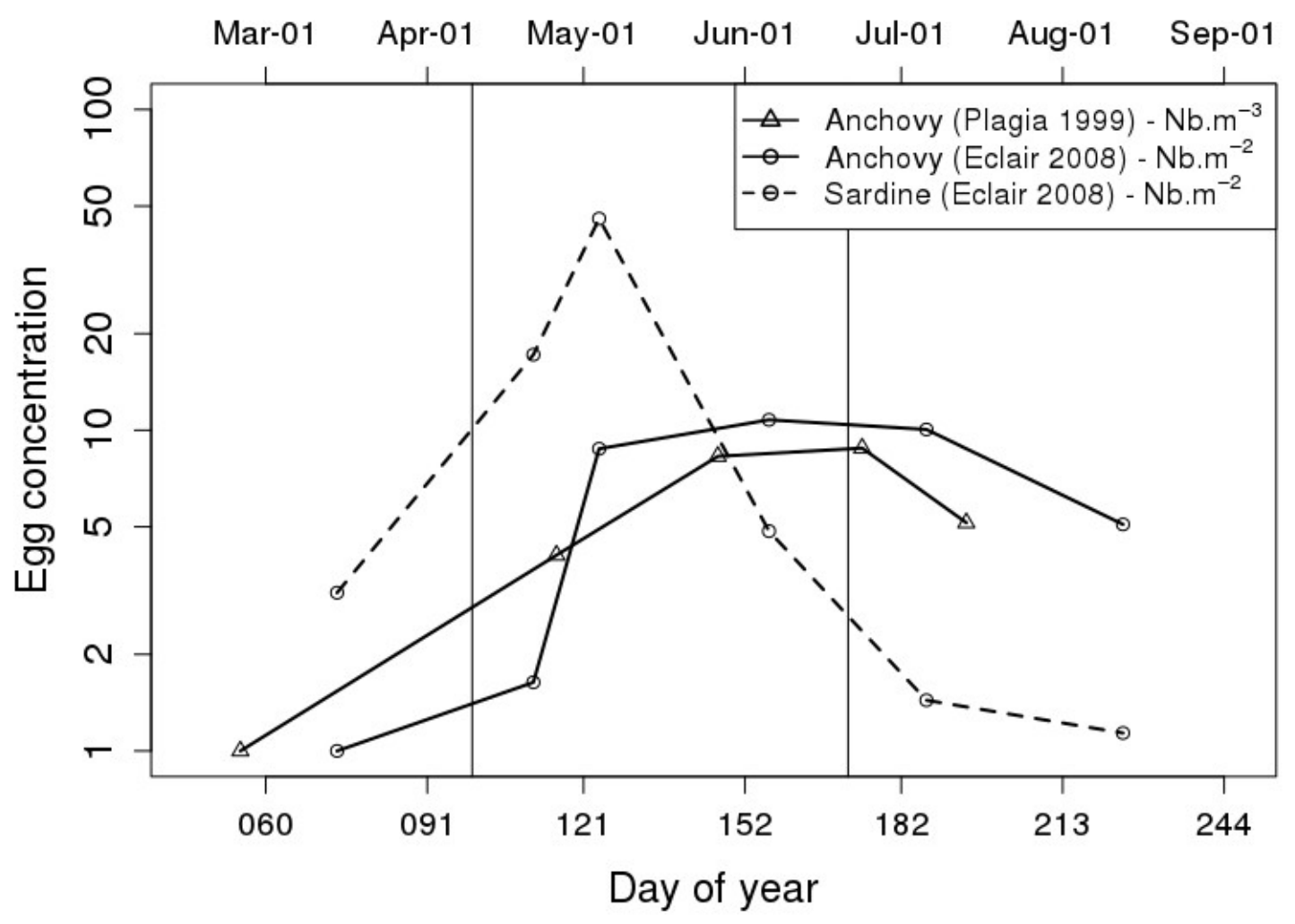

340

Fig.8. Seasonal average abundance of anchovy and sardine eggs from Plagia (1999) and Eclair (2008) monthly sampling in the Gironde plume. Different units between surveys result from different sampling strategies (see text). Note that $y$-axis is in log10-scale. Vertical lines indicate the earliest and latest corrected dates of the Pelgas survey over the 2000-2016 time-series.

Refining the temporal spawning pattern over the Bay of Biscay

The total anchovy egg abundance, collected in the Bay of Biscay during PELGAS, vs. survey date series, does not show any clear temporal pattern (Fig.9a). Using corrected dates instead of actual survey dates solely adds uncorrelated temporal variability. Very few eggs were sampled during the survey that started the earliest (in year 2000). It is followed by surveys with high or low anchovy egg abundances, uncorrelated in time. The survey that started the latest (in year 2003) was supposedly located in the peak spawning period, but displayed only low egg abundance. Spawning stock biomass (SSB) of anchovy has varied a lot during the studied period (ICES, 2016) with some 
355 very low biomass from 2005 and 2010 that led to the fishery closure. The coefficient of variation of the interannual variability in abundance as estimated by the stock assessment group is $65 \%$ while it is only $37 \%$ for sardine, as estimated by acoustic methods during the PELGAS survey. Fluctuations in SSB may be seen as a second potential cause of interannual variation in egg abundance, after the timing of observation. Normalising the anchovy egg abundance with the SSB (Fig.9b) provides a

360 fecundity index, which when plotted against the survey dates, displays its increasing trend from early April to end of June, although the regression is not significant. Indeed, the lowest fecundity at earliest date has occurred in 2000, whereas 2007 and 2011 show the opposite trend. Years such as 2013 or 2001 however show incoherency with this pattern, and 2003 remains surprisingly low for June.

A clear decrease of the sardine spawning activity is observed between early April and midJune (Fig.9c). Sardine egg abundance can be modelled as a function of the corrected survey dates using a linear model $\left(\mathrm{R}^{2}=0.57\right.$, $\mathrm{P}$-value $\left.<0.01\right)$, whereas the linear model including the actual survey dates is non-significant $\mathrm{R}^{2}=0.20$, $\mathrm{P}$-value $>0.05$ ).

(a) Anchovy

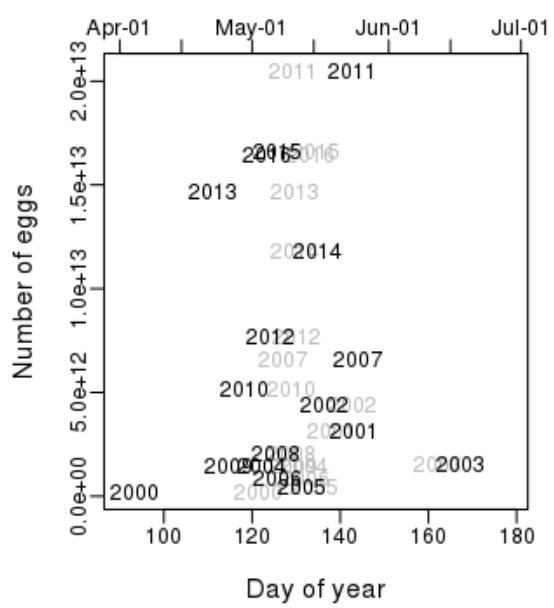

(b) Anchovy

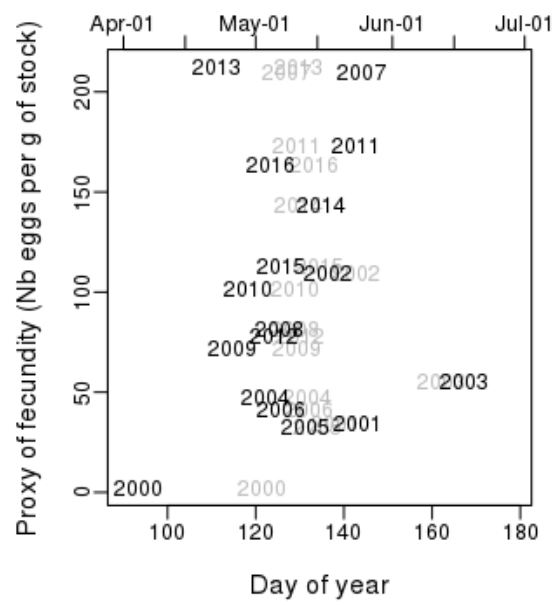

(c) Sardine

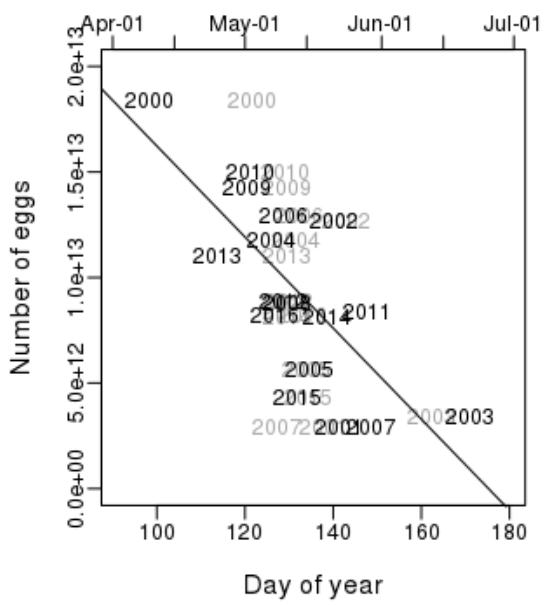

Fig.9. Total egg abundance over the Bay of Biscay versus actual date of survey (grey) and corrected date of survey (black) for anchovy (a) and sardine (c). (b) Anchovy egg abundance was divided by the estimated spawning stock biomass to provide a proxy of fecundity. 


\section{Discussion}

Positioning the surveys in the environment schedule

Seasonality in SST is quantified synoptically in every marine region thanks to remote sensing data available since the late 70's, and was described at several locations in the Bay of Biscay by Koutsikopoulos et al. (1998). It appeared from their description that minimum values occur from early March to early April with a latitudinal shift (delay from south to north) in the start of warming, and that spatial variability is minimum at that time of the year while it is maximum when warmest temperatures occur at end of August. In addition to that, our analysis over the timeseries of PELGAS surveys reveals that minimum interannual variability (Fig.2) corresponds with

385 minimum temperature at the end of the winter period, while it is maximum outside of the winter period. End of winter thus displays the minimum temperature, as well as minimum spatial and interannual variability. Winter can more generally be considered as a reset of the annual cycle of the pelagic marine ecosystem of temperate regions. In the coastal ocean, water is well mixed after stratification has broken down in fall. Nutrients have replenished over the whole water column 390 while plankton production is significantly reduced. First blooms may appear at the end of winter (Gohin et al., 2003) in haline stratified waters or wait for the onset of temperature stratification in spring. Hence winter is a good reference point for the reset of the temperature annual cycle and more generally for biological activity.

In that seasonal context, we have proposed a methodology to position our spring PELGAS

395 survey in the environment calendar. The environment calendar is reset in the previous winter, so that we have a time reference to compare the observed ecological information between our annual surveys. From that reference, we projected the degree-day conditions at time of survey in the seasonal evolution of the degree-day computed on the SST climatology, to find the equivalent environment date. Projecting the instantaneous SST of the survey in the SST climatology without 400 degree-day transformation would have been equally possible. Our degree-day metric is strongly 
correlated to the average temperature measured during the survey $\left(\mathrm{R}^{2}=0.81, \mathrm{p}\right.$-value $\left.<0.01\right)$. However, in addition to being more ecologically meaningful, degree-day has also the advantage of being less variable in time and monotonic in comparison to the highly variable and sometimes decreasing SST in spring for a given year (see Fig.2). The monotonicity and stability insure the

405 uniqueness for the date correction and robustness of the approach. The conversion of the degree-day metric to the environment date is reversible, and one can either choose to map corrected dates of survey or degree-days. In our case, as the degree-day value has no absolute meaning, we chose to map and scatterplot the corrected dates.

Years 2000 and 2003 exemplified the interest of the approach, as in addition to being

410 extreme in terms of actual survey dates, they also showed singularity with respect to the warming climatology. The methodology was spatialised for consideration of both latitudinal shift in the phasing of seasonal warming, as well as potentially rapidly changing conditions in the environment during the survey itself. The surveys have been conducted from south to north every year except for 2001. The spatialisation of our methodology, with local corrections of the actual survey dates,

415 allows some objective comparison between all surveys even with this type of unusual sampling scheme completion. It is clear that, in the context of routine ecosystemic surveys with complex logistics, our methodology is proposed to a posteriori improve the interpretation of interannual variability in the observations. But one can also imagine applying it a priori to either try to anticipate the observations, or if feasible, to adapt the sampling scheme and schedule to target some 420 specific processes.

\section{Spawning patterns}

The spatial pattern of spawning was already described for anchovy by Motos et al. (1996) from surveys between 1989 and 1992, and for both anchovy and sardine by Arbault and Lacroix 425 (1977, 1971) for the period 1964-1973 and by Planque et al. (2007) from PELGAS surveys between 2000 and 2004. The analysis of an extended, 17 years time-series derived from PELGAS data 
confirms previous observations, and the stability of the main spawning locations around May.

The south-eastern shelf has been and remains the main location for anchovy spawning in May during our PELGAS survey, with highest egg concentrations in front of the Gironde and along

430 the Spanish coast in the vicinity of the Adour plume. The egg distribution may expand offshelf in the south as in 2011 (Fig.7), which can be explained by a rather high adult biomass (ICES, 2016). Anchovy distribution is known to spread under a density-dependent effect in spring in the Bay of Biscay (Motos et al., 1996; Petitgas et al., 2014), which was also mentioned in other regions during the spawning period (e.g. in the North Aegean Sea, Schismenou et al., 2017). Motos et al. (1996)

435 described a northward extension of anchovy spawning in June, in particular over the shelf break. Our 2003 survey was conducted in June, and was even more delayed when considering our corrected dates. It confirms the aforementioned northward extension of the egg abundance, despite low egg abundances (Fig.7). In addition to the offshore spreading described above, the 2011 distribution shows a northward spreading, likely explained by a combination of density dependence 440 and delayed survey scheduling, revealed by our corrected date.

For sardine, despite a more fragmented spawning distribution and some year to year variability, generally spatial patterns remain the same over the time-series and are in agreement with historical descriptions (Arbault and Lacroix, 1977, 1971). Around May, the most stable spawning locations with highest egg abundances are found in the south-eastern shelf. When compared to 445 anchovy, the Gironde plume seems less favorable for sardine, while the Loire plume is a preferential spawning location. The shelf break in the northern part of the bay also shows high egg abundances, but their occurrences vary from year to year, while the mid-shelf area between the 100 and 150m isobaths consistently displays an absence of eggs. Sardine spawning can occur all year long in the Bay of Biscay, with a peak spawning in spring and really low egg abundances in 450 summer (Arbault and Lacroix, 1977, 1971). The years 2000 and 2003, our extreme years with reference to the environment scheduling, also reveal that the decrease of spawning after the peak occurs in late spring, with a distribution over the potential spawning habitat similar to those 
described above for both years, but with a large difference in the spawning intensity.

The temporal spawning pattern has been less described in comparison to the spatial pattern 455 for the simple reason that surveys covering the whole Bay of Biscay can not be conducted on a monthly basis. However, the successive surveys by season over several years presented in Arbault and Lacroix $(1977,1971)$ provide a general description of the annual cycle, with a continuous spawning all year long for sardine, but a peak spawning in spring and really low egg abundances in summer, while anchovy spawning is limited to spring and summer. Also for anchovy, Motos et al. (1996) described more precisely spawning activity from April to September with peak spawning in May-June, from monthly sampling in front of San Sebastian in northern Spain. Our study, with monthly sampling in the Gironde plume and detailed analysis of the PELGAS time-series, aims to refine the temporal description of the spawning activity in spring for both species. The Gironde plume is a major spawning habitat for both species, and the anomaly between actual and corrected dates for the sampled year 2008 is small enough to make this sampling effort representative of a typical year. In the Gironde plume or at the scale of the Bay of Biscay, our study confirms a peak spawning in May-June for anchovy, with a sharp increase of spawning activity in late April. For sardine, we showed that peak spawning occurs in April-May, with sharp spawning decrease in early June towards negligible intensity in summer. Our sampling did not cover the start of spawning in winter (only one sampling in the Gironde plume in late winter). However our data and the studies of Arbault and Lacroix (1971, 1977) and Stratoudakis et al., (2007) in the Catabrian Sea, suggest a significant increase of egg production in March, with a probable peak in April, after low egg production throughout the winter. Years 2000 and 2003, with dates of survey lagged by a few weeks increased the risk of missing the peak spawning, especially if those years are singular in terms of environmental scheduling.

Temperature, a descriptor of spawning habitat? 
Temperature has been systematically tested in models of spawning habitat (Planque et al., 2007) or adult distribution (Petitgas et al., 2014, Doray et al., this issue) during spawning season for

480 small pelagics in the Bay of Biscay. In all cases bottom temperature was surprisingly more relevant to describe small pelagics habitat than surface temperature, despite a similar latitudinal gradient of 2 to 3 degrees. In these habitat mapping studies, in-situ temperatures from the surveys were used. Bottom temperature was in this case not influenced by surface warming as stratification is established in most parts of the bay. The north/south temperature gradient is hence preserved near

485 the bottom, which is not the case for the surface layer as shown in Fig.3a. The rapid temperature change during the survey suggests to rather use coherent information over space and time, i.e. not biased by the survey duration, for habitat mapping puroposes. Satellite SST averaged over the duration of the survey could be a good proxy, representative of the gradient perceived by the fish. In the water column, anchovy and sardine are mostly distributed below the thermocline in spring

490 (Doray et al., this issue), making the bottom temperature a logical descriptor of their habitat. But they also spend part of the day/night cycle at surface, at least for anchovy spawning, which makes them also potentially sensitive to the surface temperature gradient. This was proposed as a strong driver for the anchovy southward spawning migration at the end of winter (Politikos et al., 2015). The choice of environment data to be used will obviously depend on the variable under 495 examination. For taxa with rapid population dynamics, such as phytoplankton, it is likely that response to the environmental driver will be fast, and it may be more appropriate to use the in-situ temperature value corresponding to the sampled species abundance. However for fish, the spatial dynamics can not respond to the rapid surface warming and is more likely to be related to the regional temperature gradient at seasonal scale. The result is a rather stable spatial organisation in 500 spring during our survey, especially for anchovy in the south, whatever the timing of the season, as characterised by our corrected survey dates. Nonetheless, in 2003, when the survey timing was extreme and more reflecting summer conditions (Fig.4,5), the spatial distribution of anchovy spawning seemed shifted north, as if anchovy had started their northward summer migration 
described in Motos et al., (1996) and Uriarte et al. (1996).

505

Degree-days, a driver of spawning phenology?

Temperature was also presented as a driver for anchovy reproduction phenology in the Bay of Biscay. According to Motos et al. (1996), anchovy spawning is triggered by surface warming and large abundances of eggs only occur above $14^{\circ} \mathrm{C}$. Arbault and Lacroix (1977) reported a range of

510 temperature for spawning of $14^{\circ}$ to $20^{\circ} \mathrm{C}$. We have already sampled some anchovy eggs in temperatures between 12 and $13^{\circ} \mathrm{C}$ in 2012 (not shown). Our results showed some potential for degree-days to explain the onset of anchovy spawning in April, with improvement when considering a fecundity proxy instead of simply egg abundances, despite some singular years (2013 with early high fecundity and 2001 and 2005 with late low fecundity). Sardine may spawn all year

515 round in the Bay of Biscay (Arbault and Lacroix, 1977) suggesting no strict temperature limitation for the temperature range of the Bay of Biscay. Surprisingly, despite this apparent lower affinity to springtime environmental conditions for reproduction, we were able to derive a model of sardine egg abundance against environment date or degree-day, which was not the case for anchovy. Reproduction is determined bioenergetically on the seasonal to annual time scale (McBride et al.,

520 2015) under a combined effect of temperature and food. Our degree-day metric integrates part of this bioenergetics variability, through its integration of the temperature and associated influence on the metabolism of organisms. It is then not a surprise that the metric was actually a better predictor of annual egg abundances than instantaneous temperature (not shown), for the part of the spawning curve we were able to describe in spring (i.e. start for anchovy and end for sardine).

The higher predictive power of the metric for forecasting sardine spawning, compared to anchovy's, may be explained by different factors. Independently of the species, the onset of spawning (the case of anchovy here), seems faster than the decrease from peak spawning (the case of sardine). A rapid process in a rapidly changing environment is certainly more difficult to capture 
in the observations, and furthermore to model, than a slower process. The difference may also be

530 species specific. The shorter lived anchovy has less age classes than sardine, which makes observations at the population scale more sensitive to the age structure. For anchovy, maturation at age 1 has been described to occur later in the season than for older fishes (Motos et al., 1996). Interannual variability in the age structure, together with SSB fluctuations, may add some variability in the anchovy fecundity observed at the population scale. Both species are

535 indeterminate, multiple batch spawners. But sardine is known to be more in the capital side of the capital-income continuum (McBride et al., 2015) than anchovy, which is comforted in the Bay of Biscay by a bioenergetics modelling study (Gatti et al., 2017). The income nature of anchovy makes its fecundity more sensitive to food condition in spring, a feature that is not captured in our degreeday metric. Conversely, sardine capital strategy would make its fecundity less sensitive to food in 540 spring and consequently more directly influenced by seasonal temperature.

To assess the ability of the degree-day metric in explaining the spatial variability in spawning, in particular the northward extension as the season progresses, a more strict definition of the degree-day should be used, without attempting to convert it into an 'environmental' date. The date conversion was relevant for the objectives of our study, but this makes the metric spatially

545 dependent on local SST climatology. A strict degree-day application would require the definition of a meaningful temperature threshold above which temperature is relevant for development. This requires specific physiology information, and would be the condition for comparing populations facing different thermal ranges (Chezik et al., 2014b), which was beyond the scope of this paper. A stricter degree-day definition would also require a meaningful starting date for the integration of the 550 degree-days. Birth date is a logical choice when assessing development duration for eggs (Tsoukali et al., 2016) or until maturity (Venturelli et al., 2010). However it needs to be adapted when assessing reproduction timing, that is decided on the seasonal to annual time scale. Reproduction timing is also highy species specific, depending on the reproduction strategy. We chose the end of winter with minimum annual temperature as a meaningful timing at the ecosystem level. This 
555 approach was relatively successful to explain the spawning phenology of sardine, and to a lesser extent, of anchovy. Building on the evidence that photoperiod was a primary cue triggering the onset of gonad development for Atlantic cod, Neuheimer and MacKenzie (2014) e.g. used autumn equinox as a start date, with some success in explaining timing of reproduction across the species' range.

560

Support of independent information from operational oceanography

The emergence of the so-called operational oceanography (OO), with the provision of synoptic environmental information through the development of earth observation systems (satellite sensors, instrumented buoys, gliders) and 3 dimensional modelling systems, offers new

565 opportunities for the interpretation of survey observations, that only represent snapshots of the ecosystem. This temporal vision may be adequate for estimating fish biomass based on fishery surveys data. However, our study showed that even targeting peak spawning, interannual variability in the environment seasonality may bias the estimation of indicators such as annual reproductive potential. To prevent this issue in the use of the daily egg production method (DEPM) for SSB

570 estimation, complementary fecundity parameters are measured simultaneously during the dedicated surveys (Bernal et al., 2012). However, interaction of sampling, time and space is still one of the limitation of the DEPM (Dickey-Collas et al., 2012). For other compartments that experience rapid changes in springtime, such as plankton, data from annual survey alone also seem insufficient for a comprehensive assessment at the seasonal scale. Many studies take these snapshot observations as

575 representative of seasonal conditions, with potential explanatory power in explaining processes acting at the seasonal to annual scale such as recruitment (Bergeron et al., 2013; Irigoien et al., 2009). OO may greatly enhance our understanding of the conditions observed during the surveys, while informing on the recent seasonal history and on the future consequences of what was observed, as well as for setting common reference points to help interpreting interannual variability.

580 Once the effect of seasonal shift is removed, the remaining part of the interannual variability can be 
properly analysed.

As OO continues developing, modelling outputs over the whole water column could provide environment information more representative of the habitats of organisms over synoptic timescales. For the degree-day approach, more accurate estimations of the experienced temperature by the 585 organism exist, provided that minimum information on its 3-D location is available. In such a case weighting the temperature by the population distribution over space and time is an option (Neuheimer and Grønkjær, 2012). With the provision of more biogeochemical parameters, we can imagine building more complex multivariate indicators with explanatory variables depending on the process under study. Also this should in turn help interpreting the interannual variability as observed

590 during the surveys in various ecosystem compartments (e.g. Perrot et al., this issue), or be included in a global, indicator-based monitoring (e.g. Doray et al., this issue).

\section{Acknowledgements}

This study was supported by Ifremer. Egg sampling during PELGAS survey has been funded by the

595 European Common Fishery Policy and Ifremer. We want to acknowledge the joint efforts of R/V Thalassa crew, as well as R/V Thalia, Gwen Drez, Côte de la Manche and Côte d'Aquitaine for the ECLAIR surveys, and all scientists who contributed to egg counting and sorting. The authors also thank N.B. Neuheimer and an anonymous reviewer for their constructive comments. 


\section{References}

600 Arbault, S., Lacroix, N., 1977. Oeufs et larves de clupeides et engraulides dans le golfe de Gascogne (1969-1973). Distribution des frayères. Relations entre les facteurs du milieu et la reproduction. Rev. Trav. Inst. Pêch. Marit. 41, 227-254.

Arbault, S., Lacroix, N., 1971. Aires de ponte de la sardine, du sprat et de l'anchois dans le golfe de Gascogne et sur le plateau Celtique. Résultats de 6 années d’études. Rev. Trav. Inst. Pêch.

605 Marit. 35, 35-56.

Autret E, Piolle JF, 2011. Product User Manual for ODYSSEA Level 3 and 4 Global and Regional Products. MYO-PUM-SST-TAC-ODYSSEA, Ifremer/CERSAT.

Bellier, E., Planque, B., Petitgas, P., 2007. Historical fluctuations in spawning location of anchovy (Engraulis encrasicolus) and sardine (Sardina pilchardus) in the Bay of Biscay during 196773 and 2000-2004. Fish. Oceanogr. 16, 1-15. doi:10.1111/j.1365-2419.2006.00410.x

Bergeron, J.-P., Koueta, N., Massé, J., 2013. Interannual fluctuations in spring pelagic ecosystem productivity in the Bay of Biscay (northeast Atlantic) measured by mesozooplankton aspartate transcarbamylase activity and relationships with anchovy population dynamics. Fish. Res. 143, 184-190. doi:10.1016/j.fishres.2013.02.006

615 Bernal, M., Somarakis, S., Witthames, P.R., van Damme, C.J.G., Uriarte, A., Lo, N.C.H., DickeyCollas, M., 2012. Egg production methods in marine fisheries: An introduction. Fish. Res. 117-118, 1-5. doi:10.1016/j.fishres.2012.01.001

Bonhomme, R., 2000. Bases and limits to using “degree.day” units. Eur. J. Agron. 13, 1-10. doi:10.1016/S1161-0301(00)00058-7

620 Borja, Á., Dauer, D.M., Grémare, A., 2012. The importance of setting targets and reference conditions in assessing marine ecosystem quality. Ecol. Indic., Marine Benthic Indicators 12, 1-7. doi:10.1016/j.ecolind.2011.06.018 
Borja, Á., Elliott, M., 2013. Marine monitoring during an economic crisis: The cure is worse than the disease. Mar. Pollut. Bull. 68, 1-3. doi:10.1016/j.marpolbul.2013.01.041

625 Bourriau, P., 1991. The ““Carre Net” (No. ICES CM 1991/L:53).

Checkley Jr, D.M., Ortner, P.B., Settle, L.R., Cummings, S.R., 1997. A continuous, underway fish egg sampler. Fish. Oceanogr. 6, 58-73. doi:10.1046/j.1365-2419.1997.00030.x

Chezik, K.A., Lester, N.P., Venturelli, P.A., 2014. Fish growth and degree-days II: selecting a base temperature for an among-population study. Can. J. Fish. Aquat. Sci. 71, 1303-1311.

630 doi:10.1139/cjfas-2013-0615

Dickey-Collas, M., Somarakis, S., Witthames, P.R., van Damme, C.J.G., Uriarte, A., Lo, N.C.H., Bernal, M., 2012. Where do egg production methods for estimating fish biomass go from here? Fish. Res. 117-118, 6-11. doi:10.1016/j.fishres.2012.01.002

Donlon, C.J., Martin, M., Stark, J., Roberts-Jones, J., Fiedler, E., Wimmer, W., 2012. The Operational Sea Surface Temperature and Sea Ice Analysis (OSTIA) system. Remote Sens. Environ. 116, 140-158. doi:10.1016/j.rse.2010.10.017

Doray, M., Badts, V., Massé, J., Duhamel, E., Huret, M., Doremus, G., Petitgas, P., 2014. Manual of fisheries survey protocols. PELGAS surveys (PELagiques GAScogne) (Manuel des protocoles de campagne halieutique Ifremer No. 30259).

640 Doray, M., Petitgas, P., Huret, M., Duhamel, E., Dupuy, C., Romagnan, J-B., Spitz, J., Authier, M. Sanchez, F. and Massé J. The PELGAS survey: ship-based integrated monitoring of the Bay of Biscay pelagic ecosystem. Under revision, this issue.

Doray, M., Hervy, C., Huret, M., and Petitgas P. Spring habitats of small pelagic fish communities in the Bay of Biscay. Under revision, this issue.

645 Gatti, P., Petitgas, P., Huret, M., 2017. Comparing biological traits of anchovy and sardine in the Bay of Biscay: A modelling approach with the Dynamic Energy Budget. Ecol. Model. 348, 
93-109. doi:10.1016/j.ecolmodel.2016.12.018

Gohin, F., Lampert, L., Guillaud, J.-F., Herbland, A., Nézan, E., 2003. Satellite and in-situ observations of a late winter phytoplankton bloom in the northern Bay of Biscay. Cont Shelf

650 Res 23, 1117-1141.

Huret, M., Bourriau, P., Gatti, P., Dumas, F., Petitgas, P., 2016. Size, permeability and buoyancy of anchovy (Engraulis Encrasicolus) and sardine (Sardina Pilchardus) eggs in relation to their physical environment in the Bay of Biscay. Fish. Oceanogr. 25, 582-597. doi:10.1111/fog.12174

655 Huret, M., Bourriau, P., Mornet, F., Dupuy C., Petitgas P. (2016). Anchovy and Sardine egg abundances and zooplankton biomass within the Gironde plume in 2008. SEANOE. http://doi.org/10.17882/47250.

ICES (2016). Report of the Working Group on Southern Horse Mackerel, Anchovy and Sardine (WGHANSA). 24-29 June 2016 Lorient, France .

660 Irigoien, X., Fernandes, J.A., Grosjean, P., Denis, K., Albaina, A., Santos, M., 2009. Spring zooplankton distribution in the Bay of Biscay from 1998 to 2006 in relation with anchovy recruitment. J. Plankton Res. 31, 1-17.

Koutsikopoulos, C., Beillois, P., Leroy, C., Taillefer, F., 1998. Temporal trends and spatial structures of the sea surface temperature in the Bay of Biscay. Oceanol. Acta 21, 335-344.

665 Koutsikopoulos, C., Le Cann, B., 1996. Physical processes and hydrological structures related to the Bay of Biscay anchovy. Sci. Mar. 60(2), 9-19.

L’Hévéder B., Speich, S., Ragueneau, O., Gohin, F., Bryère, P., 2017. Observed and projected Sea Surface Temperature seasonal changes in the Western English Channel from satellite data and CMIP5 multi-model ensemble. Int. J. Climatol., 37: 2831-2849. doi:10.1002/joc.4882

670 McBride, R.S., Somarakis, S., Fitzhugh, G.R., Albert, A., Yaragina, N.A., Wuenschel, M.J., Alonso- 
Fernández, A., Basilone, G., 2015. Energy acquisition and allocation to egg production in relation to fish reproductive strategies. Fish Fish. 16, 23-57. doi:10.1111/faf.12043

Motos, L., Uriarte, A., Valencia, V., 1996. The spawning environment of the Bay of Biscay anchovy (Engraulis encrasicolus L.). Sci. Mar. 60, 117-140.

Neuheimer, A.B., Grønkjær, P., 2012. Climate effects on size-at-age: growth in warming waters compensates for earlier maturity in an exploited marine fish. Glob. Change Biol. 18, 18121822. doi:10.1111/j.1365-2486.2012.02673.x

675 Neuheimer, A.B., MacKenzie, B.R., 2014. Explaining life history variation in a changing climate across a species’ range. Ecology 95, 3364-3375.

Neuheimer, A.B., Taggart, C.T., 2007. The growing degree-day and fish size-at-age: the overlooked metric. Can. J. Fish. Aquat. Sci. 64, 375-385. doi:10.1139/F07-003

Perrot, L., Gohin, F., Ruiz-Pino, D., Lampert, L., Huret, M., Dessier, A., Dupuy, C. and Bourriau, P. 680 Phytoplankton-derived turbidity and hydrological conditions in May in the Bay of Biscay. Under revision, this issue.

Petitgas, P., Doray, M., Huret, M., Massé, J., Woillez, M., 2014. Modelling the variability in fish spatial distributions over time with empirical orthogonal functions: anchovy in the Bay of Biscay. ICES J. Mar. Sci. J. Cons. fsu111. doi:10.1093/icesjms/fsu111

685 Petitgas, P., Goarant, A., Masse, J., Bourriau, P., 2009. Combining acoustic and CUFES data for the quality control of fish-stock survey estimates. ICES J. Mar. Sci. 66, 1384-1390.

Petitgas, P., Magri, S., Lazure, P., 2006. One-dimensional biophysical modelling of fish egg vertical distributions in shelf seas. Fish. Oceanogr. 15, 413-428. doi:10.1111/j.13652419.2006.00409.x

690 Planque, B., Bellier, E., Lazure, P., 2007. Modelling potential spawning habitat of sardine (Sardina pilchardus) and anchovy (Engraulis encrasicolus) in the Bay of Biscay. Fish. Oceanogr. 16, 
16-30. doi:10.1111/j.1365-2419.2006.00411.x

Politikos, D.V., Huret, M., Petitgas, P., 2015. A coupled movement and bioenergetics model to explore the spawning migration of anchovy in the Bay of Biscay. Ecol. Model. 313, 212-

695 222. doi:10.1016/j.ecolmodel.2015.06.036

Saulquin, B., Gohin, F., 2010. Mean seasonal cycle and evolution of the sea surface temperature from satellite and in situ data in the English Channel for the period 1986-2006. Int. J. Remote Sens. 31, 4069-4093. doi:10.1080/01431160903199155

Schismenou, E., Tsoukali, S., Giannoulaki, M., Somarakis, S., 2017. Modelling small pelagic fish 700 potential spawning habitats: eggs vs spawners and in situ vs satellite data. Hydrobiologia 788, 17-32. doi:10.1007/s10750-016-2983-4

Shephard, S., van Hal, R., de Boois, I., Birchenough, S.N.R., Foden, J., O’Connor, J., Geelhoed, S.C.V., Van Hoey, G., Marco-Rius, F., Reid, D.G., Schaber, M., 2015. Making progress towards integration of existing sampling activities to establish Joint Monitoring Programmes in support of the MSFD. Mar. Policy 59, 105-111. doi:10.1016/j.marpol.2015.06.004

Sotillo, M.G., Cailleau, S., Lorente, P., Levier, B., Aznar, R., Reffray, G., Amo-Baladrón, A., Chanut, J., Benkiran, M., Alvarez-Fanjul, E., 2015. The MyOcean IBI Ocean Forecast and Reanalysis Systems: operational products and roadmap to the future Copernicus Service. J. Oper. Oceanogr. 8, 63-79. doi:10.1080/1755876X.2015.1014663

Stratoudakis, Y., Coombs, S., de Lanzós, A.L., Halliday, N., Costas, G., Caneco, B., Franco, C., Conway, D., Santos, M.B., Silva, A., Bernal, M., 2007. Sardine (Sardina pilchardus) spawning seasonality in European waters of the northeast Atlantic. Mar. Biol. 152, 201-212. doi:10.1007/s00227-007-0674-4

715 Tsoukali, S., Visser, A.W., MacKenzie, B.R., 2016. Functional responses of North Atlantic fish eggs to increasing temperature. Mar. Ecol. Prog. Ser. 555, 151-165. doi:10.3354/meps11758 
Uriarte, A., Prouzet, P., Villamor, B., 1996. Bay of Biscay and Ibero Atlantic anchovy populations and their fisheries. Sci. Mar. 60, 237-255.

Venturelli, P.A., Lester, N.P., Marshall, T.R., Shuter, B.J., 2010. Consistent patterns of maturity and density-dependent growth among populations of walleye (Sander vitreus): application of the growing degree-day metric. Can. J. Fish. Aquat. Sci. 67, 1057-1067. doi:10.1139/F10-041 